\title{
(Invited) How to Achieve Low Thermal Resistance and High Electrothermal Ruggedness in $\mathrm{Ga}_{2} \mathrm{O}_{3}$ Devices?
}

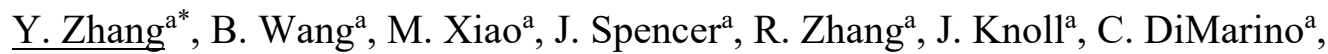 \\ G. Q. Lu ${ }^{\mathrm{a}}$, K. Sasaki ${ }^{\mathrm{b}}$, and C. Buttay ${ }^{\mathrm{c}}$ \\ ${ }^{a}$ Center for Power Electronics Systems, Virginia Polytechnic Institute and State \\ University, Virginia 24060, USA \\ ${ }^{b}$ Novel Crystal Technology Inc., Sayama 350-1328, Japan \\ ${ }^{\mathrm{c}}$ University Lyon, INSA-Lyon, CNRS, Laboratoire Ampere, Villeurbanne 69622, France \\ *E-mail: yhzhang@vt.edu
}

\begin{abstract}
Ultra-wide bandgap gallium oxide $\left(\mathrm{Ga}_{2} \mathrm{O}_{3}\right)$ devices have recently emerged as promising candidates for power and RF electronics. The low thermal conductivity of $\mathrm{Ga}_{2} \mathrm{O}_{3}$ has arguably been the most serious concern for these devices. Despite many simulation studies, there still lacks an experimental report on the thermal resistance and electrothermal ruggedness of a large-area, packaged $\mathrm{Ga}_{2} \mathrm{O}_{3}$ device. Recently, our team for the first time demonstrated largearea $\mathrm{Ga}_{2} \mathrm{O}_{3}$ devices with different packaging configurations and measured the thermal resistance and surge current capabilities of these packaged $\mathrm{Ga}_{2} \mathrm{O}_{3}$ devices. This paper reviews the key results in our efforts. It is shown that, contrary to some popular belief, $\mathrm{Ga}_{2} \mathrm{O}_{3}$ devices with proper packaging can achieve high thermal performance in both short transients and the steady state. The double-side-packaged $\mathrm{Ga}_{2} \mathrm{O}_{3}$ Schottky rectifiers show a junctionto-case thermal resistance lower than that of the similarly-rated commercial $\mathrm{SiC}$ Schottky rectifiers. In addition, these $\mathrm{Ga}_{2} \mathrm{O}_{3}$ rectifiers can survive a higher peak surge current as compared to $\mathrm{SiC}$ rectifiers. The critical enabler for these excellent performances is the direct junction cooling with minimal heat going through the $\mathrm{Ga}_{2} \mathrm{O}_{3}$ chip. Our work proves the viability of $\mathrm{Ga}_{2} \mathrm{O}_{3}$ devices for high power applications and manifests the significance of packaging for their die-level thermal management.
\end{abstract}

\section{Introduction}

Ultra-wide-bandgap (UWBG) semiconductor gallium oxide $\left(\mathrm{Ga}_{2} \mathrm{O}_{3}\right)$ has been promoted for years as a promising candidate for power electronics and RF applications, due to its high critical electrical field (E-field), controllable n-type doping, and the availability of large-diameter wafers by the melt growth $(1,2)$. Recently, kilovolt-class $\mathrm{Ga}_{2} \mathrm{O}_{3}$ Schottky barrier diodes (SBDs) have been demonstrated with a peak junction E-field exceeding the critical E-field of $\mathrm{GaN}$ and $\mathrm{SiC}$ (3-5). However, a fundamental limitation of $\mathrm{Ga}_{2} \mathrm{O}_{3}$ is its low thermal conductivity $\left(k_{\mathrm{T}}=0.1-0.3 \mathrm{Wcm}^{-1} \mathrm{~K}^{-1}\right)$, which is about $1 / 6$ of the $k_{\mathrm{T}}$ of $\mathrm{Si}, 1 / 10$ of $\mathrm{GaN}$, and $1 / 20$ of $\mathrm{SiC}$. The resulting high thermal resistance of $\mathrm{Ga}_{2} \mathrm{O}_{3}$ chip has brought serious concerns regarding the current and power scalability of $\mathrm{Ga}_{2} \mathrm{O}_{3}$ devices and their electrothermal ruggedness. As a result, questions have long persisted on the true viability of $\mathrm{Ga}_{2} \mathrm{O}_{3}$ devices for industrial power and $\mathrm{RF}$ applications. 
Despite many simulation and modeling works on the thermal management of $\mathrm{Ga}_{2} \mathrm{O}_{3}$ devices (6-9), there has been no experimental report on the packaging and thermal management of large-area $\mathrm{Ga}_{2} \mathrm{O}_{3}$ devices. The lack of these data makes it difficult to compare $\mathrm{Ga}_{2} \mathrm{O}_{3}$ with commercial device technologies (e.g., $\mathrm{Si}, \mathrm{SiC}, \mathrm{GaN}$ ) and evaluate the true application space of $\mathrm{Ga}_{2} \mathrm{O}_{3}$ devices. Some recent works characterized the channel (or junction) temperature in $\mathrm{Ga}_{2} \mathrm{O}_{3}$ devices (10-12), and developed various methods to reduce the temperature $(13,14)$, but all of these devices have small areas with a current much lower than $1 \mathrm{Amp}$, and none of these devices are packaged.

To fill these gaps, our team for the first time demonstrated large-area, packaged $\mathrm{Ga}_{2} \mathrm{O}_{3}$ devices and characterized their thermal resistance and transient electrothermal ruggedness. This paper reviews the key results, with the details published in (15-18). Vertical $\mathrm{Ga}_{2} \mathrm{O}_{3}$ SBDs with a $3 \times 3 \mathrm{~mm}^{2}$ Schottky contact area were fabricated, showing a forward current over $20 \mathrm{~A}$ and a breakdown voltage $(B V)$ over $600 \mathrm{~V}$. Small-area $\mathrm{Ga}_{2} \mathrm{O}_{3}$ SBDs fabricated on the same wafer exhibited capabilities to operate at high temperatures up to $600 \mathrm{~K}(18)$. The fabricated large-area SBDs were then packaged in the bottom- and double-side-cooling configurations using the nanosilver sintering as the die attach.

To evaluate the device's steady-state thermal performance, the junction-to-case thermal resistance $\left(R_{\theta \mathrm{JC}}\right)$ of a double-side-packaged $\mathrm{Ga}_{2} \mathrm{O}_{3}$ SBD was measured in the bottom-side- and junction-side-cooling configurations. The $R_{\theta \mathrm{JC}}$ is an essential metric in the datasheet of any commercial power device. The $R_{\theta \mathrm{JC}}$ characterization was based on the transient dual interface method, i.e., JEDEC 51-14 standard (19). The $R_{\theta \mathrm{JC}}$ of the

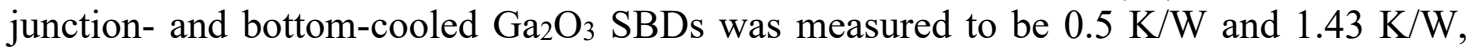
respectively. The former $R_{\theta \mathrm{JC}}$ was found to be lower than that of similarly-rated commercial SiC SBDs. This low $R_{\theta J C}$ is attributable to the heat extraction directly from the Schottky junction instead of through the $\mathrm{Ga}_{2} \mathrm{O}_{3}$ chip.

Surge current is an essential ruggedness metric listed in any power diode's datasheet and the most important indicator of a device's transient electrothermal ruggedness (15, 20). It measures the device's capability of temporarily sustaining a current much higher than the rated current. A surge-current test circuit was prototyped to produce a 10-mswide half-sinusoidal current waveform based on the JEDEC standard. The surge-current tests revealed a critical surge current of 37.5 A for the single-side-packaged $\mathrm{Ga}_{2} \mathrm{O}_{3} \mathrm{SBD}$ and $68 \mathrm{~A}$ for the double-side-packaged $\mathrm{Ga}_{2} \mathrm{O}_{3}$ SBD. The latter $\mathrm{Ga}_{2} \mathrm{O}_{3}$ SBD shows a ratio between the peak surge current and the rated current higher than that of the similarlyrated commercial SBDs. This superior capability is attributable to the small temperature dependence of on-resistance $\left(R_{\mathrm{ON}}\right)$ of $\mathrm{Ga}_{2} \mathrm{O}_{3}$ devices, which strongly reduces the thermal runaway, and the double-side-cooled packaging, which allows direct junction cooling.

Our results have removed some critical concerns regarding the thermal performance and ruggedness of $\mathrm{Ga}_{2} \mathrm{O}_{3}$ devices and suggested the strong need for the device-packaging co-design for $\mathrm{Ga}_{2} \mathrm{O}_{3}$ devices. The co-optimization should also be performed in the context of circuit operations, e.g., transient dynamics in a surge (short) current profile.

\section{Bare-Die Device: Fabrication and High-Temperature Characteristics}

High-temperature characterizations of bare-die devices are the pre-requisites for the thermal study of packaged $\mathrm{Ga}_{2} \mathrm{O}_{3}$ devices. Hence, we first fabricated small-area vertical 
$\mathrm{Ga}_{2} \mathrm{O}_{3}$ SBDs $(3,18)$. A critical knowledge gap of $\mathrm{Ga}_{2} \mathrm{O}_{3}$ devices in the literature was the lack of reports on the high-voltage blocking capability at high temperatures. This gap makes the applicability of $\mathrm{Ga}_{2} \mathrm{O}_{3}$ devices in harsh-environment power applications questionable. To this end, we focused on evaluating the high-voltage blocking capabilities of our bare-die $\mathrm{Ga}_{2} \mathrm{O}_{3}$ SBDs at high temperatures.

The commercially available $\mathrm{Ga}_{2} \mathrm{O}_{3}$ wafer from Novel Crystal Technologies consists of a $10-\mu \mathrm{m}$ Si-doped $\mathrm{n}-\mathrm{Ga}_{2} \mathrm{O}_{3}$ epitaxial drift layer (net donor concentration $\sim 2 \times 10^{16} \mathrm{~cm}^{-3}$ ) grown on a 2-inch $\mathrm{n}^{+}-\mathrm{Ga}_{2} \mathrm{O}_{3}(001)$ substrate $\left(\mathrm{Sn}: 1.3 \times 10^{19} \mathrm{~cm}^{-3}\right)$. The substrate was thinned down to a thickness of $500 \mu \mathrm{m}$. The device fabrication is detailed in $(3,18,21$, 22). A layer of $\mathrm{SiO}_{2}$ was deposited, followed by patterned wet etch, which functions as the hard mask for $\mathrm{Ga}_{2} \mathrm{O}_{3}$ mesa etch. Then a 1- $\mu$ m-thick spin-on-glass (SOG) was deposited and selectively wet etched to produce a controllable bevel angle (3), which functions as the field plate (FP) dielectrics. A Ti/Au Ohmic contact is formed on the backside of the substrate, and a Ni/Au stack is deposited as the Schottky and FP metals. The device structure is illustrated in Fig. 1(a). Fig. 1(b) shows scanning electron microscopy (SEM) images of the edge termination region, revealing a bevel angle of $45^{\circ}$ in the FP dielectrics and $\mathrm{Ga}_{2} \mathrm{O}_{3}$ mesa. Fig. 1(c) and (d) show the forward I-V and highbias reverse $\mathrm{I}-\mathrm{V}$ characteristics of the fabricated $\mathrm{Ga}_{2} \mathrm{O}_{3}$ SBDs, respectively, demonstrating the capability of blocking at least $500 \mathrm{~V}$ up to $600 \mathrm{~K}$. The high-bias leakage current can be explained by a combination of the thermionic-field emission (TFE) across the Schottky barrier and the electron hopping via the defect states in the depletion region (18). The latter mechanism was widely reported in other wide-bandgap high-voltage power devices, e.g., GaN (23-27) and $\mathrm{SiC}$ (28-30). These results verify the high-temperature stability of high-voltage $\mathrm{Ga}_{2} \mathrm{O}_{3}$ SBDs.
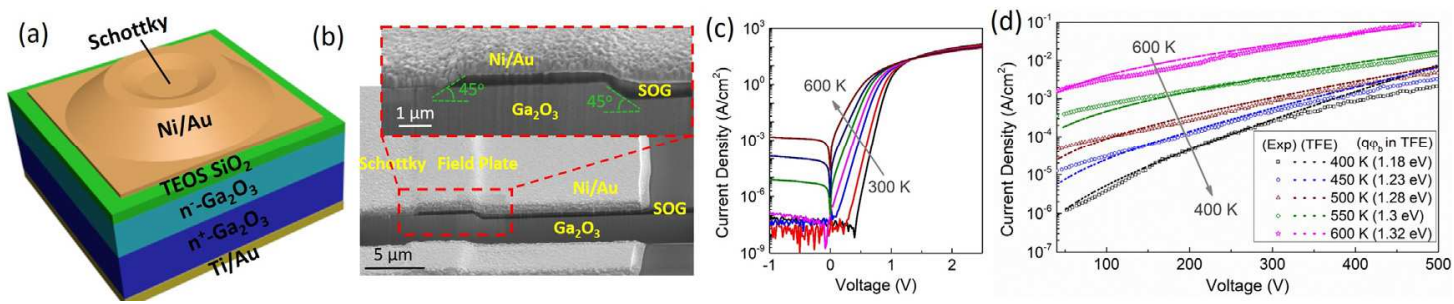

Figure 1. (a) Schematic of the fabricated small-area $\mathrm{Ga}_{2} \mathrm{O}_{3} \mathrm{SBD}$, and (b) the SEM image of the edge termination region. (c) Forward and (d) reverse I-V characteristics of the $\mathrm{Ga}_{2} \mathrm{O}_{3} \mathrm{SBD}$ at various temperatures from $300 \mathrm{~K}$ to $600 \mathrm{~K}$.
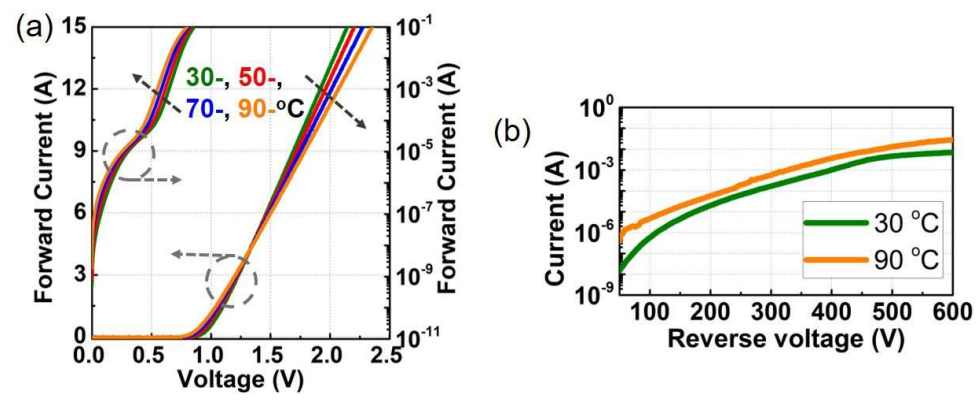

Figure 2. (a) Forward and (b) reverse $\mathrm{I}-\mathrm{V}$ characteristics of the large-area vertical $\mathrm{Ga}_{2} \mathrm{O}_{3}$ $\mathrm{SBD}$ at various temperatures from $30{ }^{\circ} \mathrm{C}$ to $90{ }^{\circ} \mathrm{C}$. 
Subsequently, large-area vertical $\mathrm{Ga}_{2} \mathrm{O}_{3}$ SBDs with a Schottky contact area of $3 \times 3$ $\mathrm{mm}^{2}$ were fabricated on the same wafer. To simplify the device structure to maximize the device fabrication yield (and leave margin for packaging yield), our first-generation large-area $\mathrm{Ga}_{2} \mathrm{O}_{3}$ SBDs employ only a planar FP without the mesa structure. According to the simulation (3), a small FP bevel angle can reduce the E-field crowding. Hence, a $\sim 15^{\circ}$ bevel angle in the FP was fabricated. Fig. 2(a) and (b) show the forward and reverse $\mathrm{I}-\mathrm{V}$ characteristics of the fabricated large-area $\mathrm{Ga}_{2} \mathrm{O}_{3}$ SBDs, respectively, revealing a $0.83 \mathrm{~V}$ turn-on voltage $\left(V_{\mathrm{ON}}\right)$ extracted at $1 \mathrm{~A} / \mathrm{cm}^{2}$, a forward current of $15 \mathrm{~A}$ at $2.15 \mathrm{~V}$, an on/off ratio of $\sim 10^{10}$, and a capability to block at least $600 \mathrm{~V}$.

\section{Device Packaging}

The packaging started with depositing 100-nm-thick Ti and 200-nm-thick Ag on both sides of contacts as adhesion layers to the sintered nanosilver bond-line. Ti also serves as a barrier layer to prevent metal diffusion during the sintering process. A nanosilver paste from NBE Technologies was then used for the die attach by a pressureless sintering process in air $(31,32)$. More details on the sintering process were reported in (16). Devices with single-side- and double-side-cooled packages were then prototyped, as shown in Fig. 3(a) and (b). For the single-side-cooled package, the cathode of the $\mathrm{Ga}_{2} \mathrm{O}_{3}$ chip was sintered on a 1-mm thick Ag plate, and wire-bonds were attached on the top anode. For the double-side-cooled package, each terminal of the $\mathrm{Ga}_{2} \mathrm{O}_{3}$ chip was sintered on a 1-mm thick Ag plate. Fig. 3(c) shows a double-side-cooled package mounted on a ceramic substrate with wire-bond connections, ready for surge tests. Substrate and wire-bonds were not used for the thermal resistance tests.

(a)

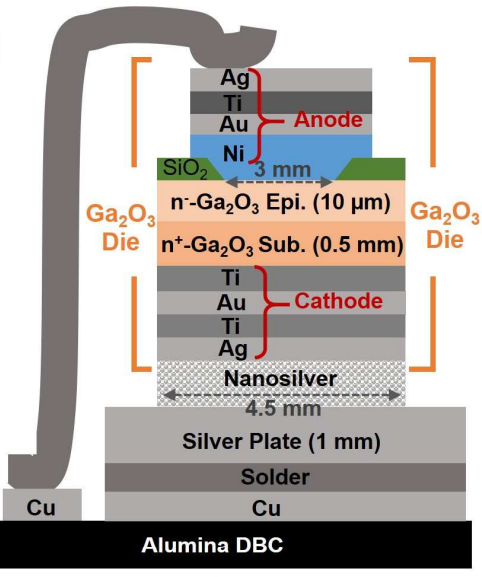

(c)

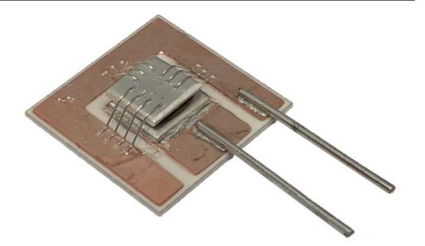

(b)

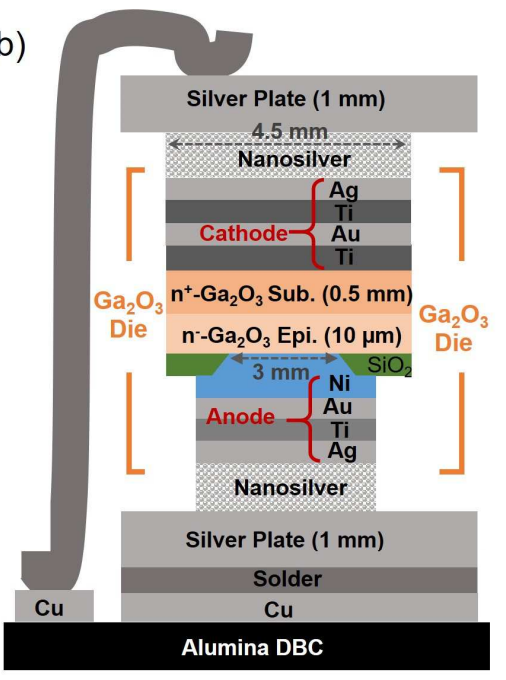

Figure 3. Schematic of the large-area $\mathrm{Ga}_{2} \mathrm{O}_{3}$ packaged in (a) single-side-cooled and (b) double-side-cooled configurations. (c) Photo of a double-side-packaged device.

\section{Thermal Resistance Measurement}

The $R_{\theta \mathrm{JC}}$ measurement was based on the transient dual interface method (TDIM) (i.e., JEDEC 51-14 standard (19)). This TDIM method relies on two transient thermal 
impedance curves $(Z \sim t)$ measured with different contact thermal resistances between the package case surface and the ambient. The $Z$ value at the separation point of the two curves is extracted as the device steady-state $R_{\theta J C}(19)$.

Fig. 4(a) shows our $R_{\theta \mathrm{JC}}$ measurement set-up using an Analysis Tech Phase 12B Semiconductor Thermal Analyzer. The $\mathrm{Ga}_{2} \mathrm{O}_{3} \mathrm{SBD}$ was placed on a water-cooling cold plate with a $26^{\circ} \mathrm{C}$ constant temperature. An indium foil was attached to each Ag plate to conduct electric signals. The top plastic clamp has very low thermal conductivity, ensuring the heat extraction dominantly towards the bottom water-cooling plate. Fig. 4(b) and (c) show the $R_{\theta J \mathrm{C}}$ measurement of the double-side packaged $\mathrm{Ga}_{2} \mathrm{O}_{3}$ SBD under bottom-side- and junction-side-cooling.

The $R_{\theta \mathrm{JC}}$ measurements started by applying a dc bias to the SBD for self-heating until the junction reaches the steady state (junction temperature $=T_{\mathrm{j}}$ ). The power was then cut off, and the $T_{\mathrm{j}}$ evolution was measured by monitoring a thermo-sensitive electrical parameter (TSEP) (33). For our $\mathrm{Ga}_{2} \mathrm{O}_{3}$ SBDs, the TSEP was selected as the forward voltage at $10 \mathrm{~mA}$, which showed good linearity with $T_{\mathrm{j}}$. With $T_{\mathrm{j}}$, the $Z \sim t$ curve was calculated. For each $R_{\theta \mathrm{JC}}$ test, two $Z \sim t$ curves were acquired by using two different thermal interface materials (TIMs) between the indium foil and the cold plate, i.e., some silicone oil (lower $k_{\mathrm{T}}$ ) and some thermal grease (higher $k_{\mathrm{T}}$ ). The separation point of the two heating $Z \sim t$ curves was extracted as $R_{\theta J \mathrm{JC}}(19)$. Fig. 4(d) and (e) show the measured $Z \sim t$ curves of our packaged $\mathrm{Ga}_{2} \mathrm{O}_{3}$ SBD in the bottom-side- and junction-side-cooling schemes, respectively, revealing a much lower $R_{\theta \mathrm{JC}}(0.5 \mathrm{~K} / \mathrm{W})$ under the junction-side cooling as compared to the $R_{\theta \mathrm{JC}}(1.43 \mathrm{~K} / \mathrm{W})$ under the bottom-side cooling.
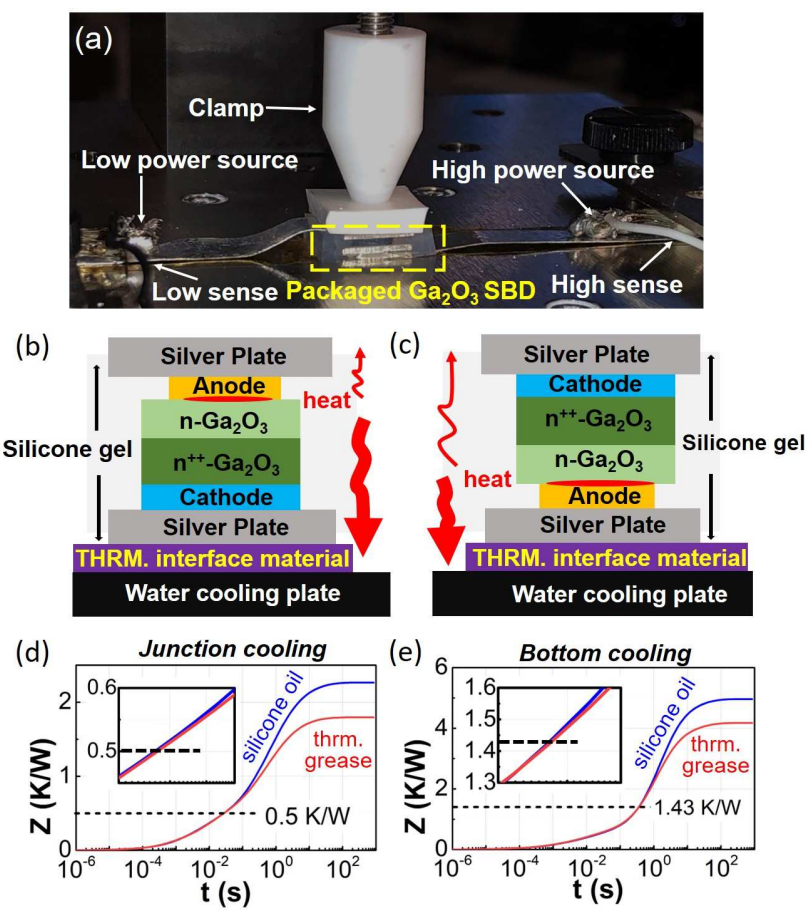

Figure 4. (a) Photo of the thermal resistance test setup. Schematic of $R_{\theta \mathrm{JC}}$ measurements under (b) bottom-side cooling and (c) junction-side cooling. $\mathrm{Z} \sim \mathrm{t}$ curves of the $\mathrm{Ga}_{2} \mathrm{O}_{3}$ SBD measured with two TIMs under (d) junction-side- and (e) bottom-side-cooling, and the extracted $R_{\theta \mathrm{JC}}$ under two cooling schemes. 
Table I compares the $R_{\theta \mathrm{JC}}$ of our $\mathrm{Ga}_{2} \mathrm{O}_{3}$ SBDs against commercial $600-\mathrm{V}$ SiC SBDs with a similar current rating and different TO-series packages. The $R_{\theta J \mathrm{C}}$ of our junctionside cooled $\mathrm{Ga}_{2} \mathrm{O}_{3}$ SBD is lower than that of commercial SiC SBDs with a similar package size and current rating. This suggests the feasibility of employing the proper packaging to overcome the low $k_{\mathrm{T}}$ of $\mathrm{Ga}_{2} \mathrm{O}_{3}$.

TABLE I. Thermal resistance comparison between $\mathrm{Ga}_{2} \mathrm{O}_{3}$ SBDs and commercial $\mathrm{SiC}$ SBDs with similar current ratings and package sizes.

\begin{tabular}{|c|c|c|c|c|c|c|}
\hline Device & Package & Package Size ${ }^{*}\left(\mathrm{~mm}^{2}\right)$ & $\mathrm{V}_{\mathrm{ON}}(\mathrm{V})$ & $\mathrm{I}_{\mathrm{F}}(\mathrm{A})^{* *}$ & Cooling & $R_{\theta \mathrm{JC}}(\mathrm{K} / \mathrm{W})$ \\
\hline \multirow{2}{*}{$\begin{array}{c}\mathrm{Ga}_{2} \mathrm{O}_{3} \mathrm{SBD} \\
\text { (this work) }\end{array}$} & \multirow{2}{*}{$\begin{array}{l}\text { Double- } \\
\text { side }\end{array}$} & \multirow{2}{*}{$7.3 \times 7.3$} & \multirow{2}{*}{0.83} & \multirow{2}{*}{13} & Junction & 0.5 \\
\hline & & & & & Bottom & 1.43 \\
\hline $\begin{array}{c}\mathrm{SiC} S B D \\
(\mathrm{C} 3 \mathrm{D} 10060 \mathrm{G}) \\
\end{array}$ & TO-263-2 & $6.5 \times 7.9$ & 0.85 & 18 & Bottom & 1.2 \\
\hline $\begin{array}{c}\mathrm{SiC} \mathrm{SBD} \\
(\mathrm{E} 3 \mathrm{D} 08065 \mathrm{G}) \\
\end{array}$ & TO-263-2 & $6.5 \times 7.9$ & 0.85 & 14.5 & Bottom & 1.47 \\
\hline $\begin{array}{c}\mathrm{SiC} \mathrm{SBD} \\
(\mathrm{C} 6 \mathrm{D} 04065 \mathrm{E}) \\
\end{array}$ & \begin{tabular}{|c} 
TO-252- \\
2 \\
\end{tabular} & $5.2 \times 4.3$ & 0.85 & 12 & Bottom & 2.89 \\
\hline
\end{tabular}

*Size of the die-attached thermal pad. **Forward current at $2 \mathrm{~V}$.

\section{Surge Current Test}

Fig. 5(a) and (b) show the surge-current test circuit and the prototype, respectively. The working principle and implementation of the test circuit are detailed in $(16,20)$. A 10-ms-wide half-sinusoidal current waveform was produced by a resonance circuit comprising a 2.2- $\mathrm{mH}$ inductor and a $4.7-\mathrm{mF}$ capacitor). SiC MOSFETs were used as the control switches. The peak surge current $\left(I_{\text {peak }}\right)$ was stepped up by increasing the power supply voltage $\left(V_{\mathrm{DC}}\right)$. After each single-pulse surge-current test, the device was measured on the curve tracer to identify any possible degradation. It should be noted that the device cooling in this section is in the context of a $10-\mathrm{ms}$ transient instead of the steady state. The thickness of Ag plate $(1 \mathrm{~mm})$ is designed to ensure that the heat diffusion is confined in the plate during the 10 -ms transient $(15,16)$, while the outer solder, $\mathrm{DBC}$, and wire bond do not contribute to the heat dissipation in this transient.

Fig. 5(c) and (d) show the current/voltage waveforms in the surge current tests with increased $I_{\text {peak }}$ for the $\mathrm{Ga}_{2} \mathrm{O}_{3}$ SBDs with the bottom-side and double-side packages. The $\mathrm{Ga}_{2} \mathrm{O}_{3}$ SBD with the bottom-side-cooling package was found to fail in the surge test with an $I_{\text {peak }}$ of 39 A. The failure $I_{\text {peak }}$ is much higher $(70 \mathrm{~A})$ in the double-side-cooled SBD. Fig. 5(e) and (f) show the surge I-V loops of the SBDs with both types of packages. Both I-V loops are clockwise, due to the increased $R_{\text {on }}$ at higher $T_{\mathrm{j}}$, and the loop area is correlated to the $R_{\text {on }}$ (and $T_{\mathrm{j}}$ ) increase in the surge test. With a similar $I_{\text {peak }}($ e.g., $30 \mathrm{~A}$ ), the loop area of the double-side-cooled SBD is smaller than that of the bottom-sidecooled SBD, suggesting a smaller $T_{\mathrm{j}}$ increase. Transfer characteristics of the double-sidecooled SBD were measured after each surge test with increased $I_{\text {peak. }}$. Almost no device

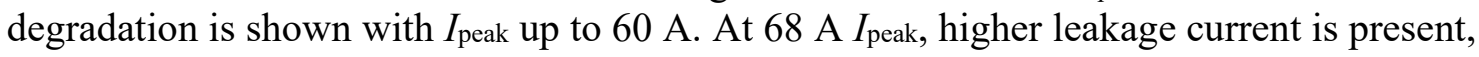
suggesting that degradation emerges in the Schottky contact. 

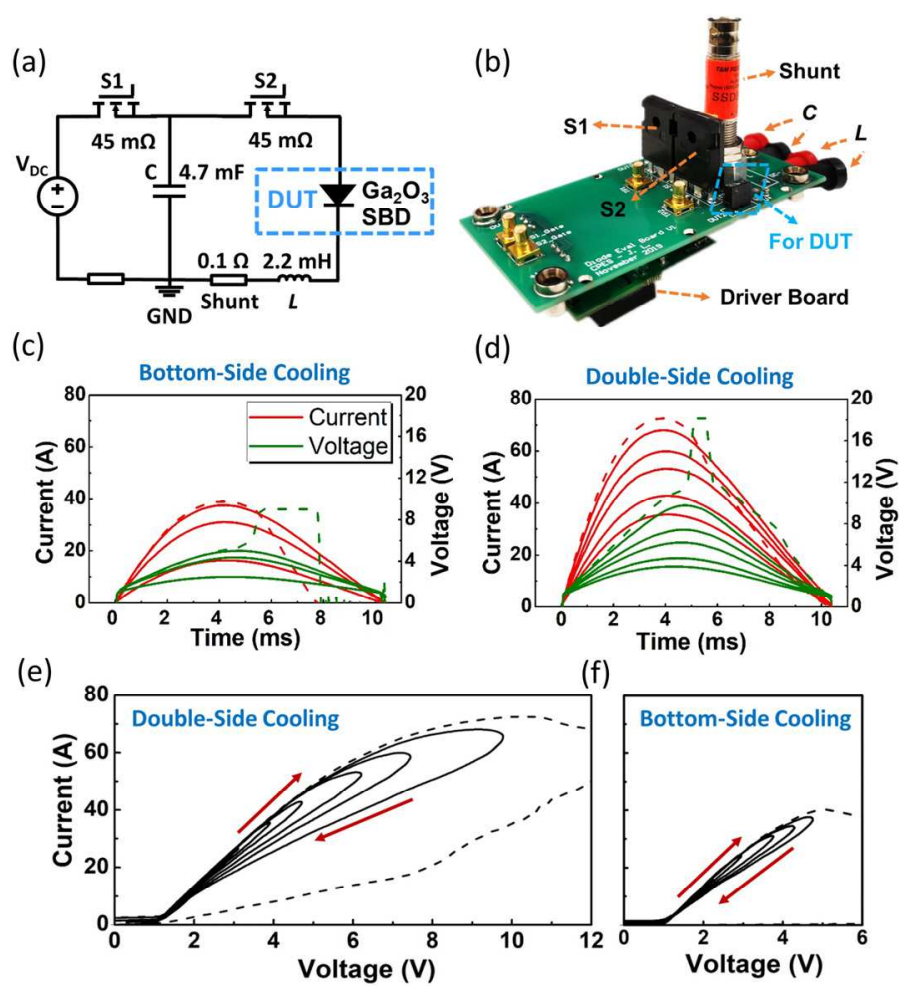

Figure 5. (a) Circuit diagram and (b) photo of the surge current test board.

Current/voltage waveforms of the (c) bottom-side- and (d) double-side-cooled $\mathrm{Ga}_{2} \mathrm{O}_{3}$ SBDs in the surge current tests. I-V loops of the (e) double-side- and (f) bottom-sidecooled devices.

An important device ruggedness metric for practical power applications is the ratio between the maximum $I_{\text {peak }}$ in 10-ms surge current tests and the rated current. The rated currents of the bottom-side-cooled and double-side-cooled $\mathrm{Ga}_{2} \mathrm{O}_{3}$ SBDs were determined by the calibrated static electrothermal simulations (16) when the $T_{\mathrm{j}}$ reaches $150{ }^{\circ} \mathrm{C}$, being 6.2 A for the bottom-side-cooled device and 9.2 A for the double-side-cooled device. For comparison, several commercial SiC SBDs with similar ratings (600-V voltage rating and 4 11 A current ratings) were tested in the same surge current test setup to identify their maximum surge currents. As shown in Table II, despite the low $k_{\mathrm{T}}$ of $\mathrm{Ga}_{2} \mathrm{O}_{3}(1 / 20$ of $\mathrm{SiC})$, the fabricated $\mathrm{Ga}_{2} \mathrm{O}_{3}$ SBDs, particularly the ones with double-side-cooling package, show comparable, or even superior surge current capabilities as compared to the similarly-rated commercial SiC SBDs.

TABLE II. Comparison of the surge current capability of $\mathrm{SiC}$ and $\mathrm{Ga}_{2} \mathrm{O}_{3}$ Schottky barrier diodes

\begin{tabular}{||c||c||c||c||}
\hline Device & $\begin{array}{c}\text { Rated } \\
\text { Current (A) }\end{array}$ & $\begin{array}{c}\text { Max Surge } \\
\text { Current (A) }\end{array}$ & $\begin{array}{c}\text { Max surge current } \\
\text { over rated current }\end{array}$ \\
\hline \hline $\mathrm{SiC} \mathrm{SBD} \mathrm{(CSD01060A)}$ & 4 & 20.3 & 5.1 \\
\hline \hline $\mathrm{SiC} \mathrm{SBD} \mathrm{(CSD02060A)}$ & 8 & 26.9 & 3.36 \\
\hline \hline $\mathrm{SiC}$ SBD (CSD03060A) & 11 & 31.8 & 2.89 \\
\hline \hline Bottom-side-packaged $\mathrm{Ga}_{2} \mathrm{O}_{3} \mathrm{SBD}$ & 6.2 & 37.5 & 6.05 \\
\hline \hline Double-side-packaged $\mathrm{Ga}_{2} \mathrm{O}_{3} \mathrm{SBD}$ & 9.2 & 68 & 7.4 \\
\hline
\end{tabular}




\section{Mixed-Mode Electrothermal Simulations}

To understand the electrothermal dynamics within the device structure, mixed-mode electrothermal TCAD simulations were performed in Silvaco Atlas. The mixed-mode simulation combines physics-based device models and circuit arrangements, enabling to reveal the device internal dynamics in at any switching transient. Some exemplar mixedmode TCAD simulations for power devices are available in (34-36). In this work, selfconsistent electrothermal device models are solved in a circuit arrangement consistent with that shown in Fig. 5(a). The electrothermal model settings and boundary conditions are similar to (37). The temperature-dependent $k_{\mathrm{T}}$, heat capacity, and electron mobility models for $\mathrm{Ga}_{2} \mathrm{O}_{3}$ and nanosilver die attach are detailed in (16).

Fig. 6(a)-(d) show the simulated distributions of heat flux and temperatures in the double-side-cooled SBD at the peak $T_{\mathrm{j}}$ transient in the surge current test with $I_{\text {peak }} \sim 68 \mathrm{~A}$. Fig. 6(a) and (c) show the simulated contours in the entire device structure, while Fig. 6(b) and (d) show the junction region. The heat flux distribution in the double-sidecooled SBD reveals that most heat is dissipated directly from the Schottky junction instead of through the $\mathrm{Ga}_{2} \mathrm{O}_{3}$ die. This explains the lower $T_{\mathrm{j}}$ in the double-side-cooled

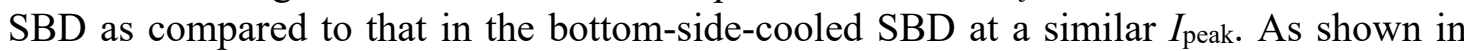
Fig. 6(d), the simulated peak temperature is located within the $\mathrm{Ga}_{2} \mathrm{O}_{3}$ drift layer in the double-side-cooled SBD. By contrast, in the usual static operations of a SBD, the peak temperature is located at the Schottky junction. The double-side package moves the peak temperature from the Schottky contact region into the robust bulk $\mathrm{Ga}_{2} \mathrm{O}_{3}$, which allows the device to sustain a higher $T_{\mathrm{j}}$ before degradation of the Schottky contact.

(a)

(c)

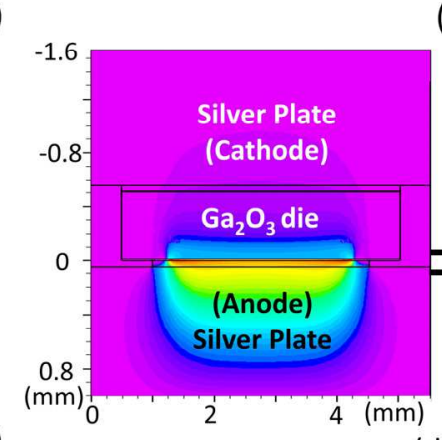

(b)

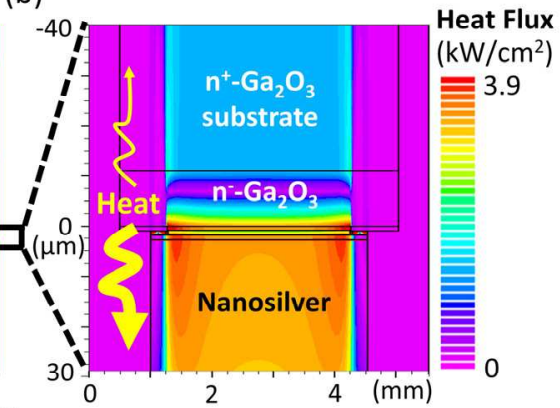

(d)

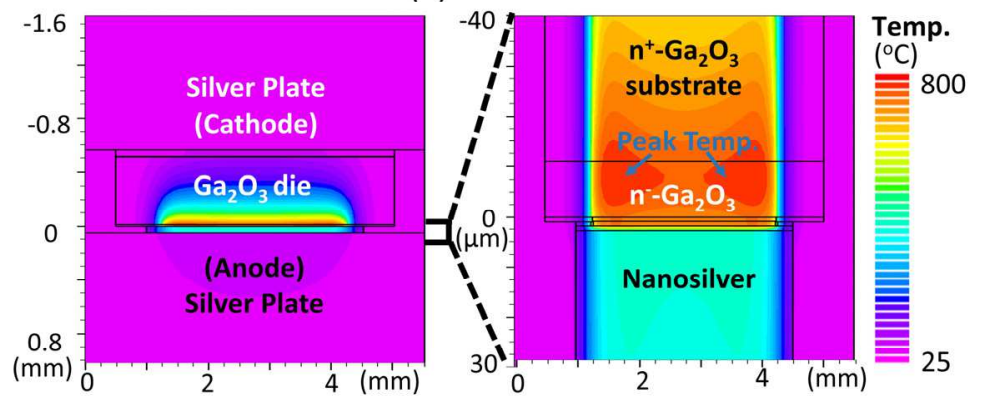

Figure 6. Simulated heat flux contour in the (a) entire packaged device and (b) device junction region, and simulated temperature distributions in the (c) entire device and (d) junction region, in a double-side-packaged $\mathrm{Ga}_{2} \mathrm{O}_{3} \mathrm{SBD}$ at the peak $T_{\mathrm{j}}$ transient in the surge current test with $68 \mathrm{~A} T_{\text {peak. }}$ 


\section{Strategies for Further Improvement}

The well-calibrated electrothermal simulations allow an exploration of the further improvement in the steady-state and transient thermal performance of $\mathrm{Ga}_{2} \mathrm{O}_{3}$ devices. Fig. 7 shows the simulated junction-to-coolant (-ambient) thermal resistance as a function of heat transfer coefficient (HTC), in which the HTC represents different cooling methods, for our vertical $\mathrm{Ga}_{2} \mathrm{O}_{3}$ SBDs in the bottom-, junction- and double-side cooling schemes. The results suggest that the junction-cooling is essential for $\mathrm{Ga}_{2} \mathrm{O}_{3}$ devices, as it allows over $60-70 \%$ reduction in the junction-to-ambient thermal resistance. The double-sidecooling can further reduce the junction-to-ambient thermal resistance by $30 \sim 40 \%$. An HTC over $10^{3} \mathrm{~W} / \mathrm{m}^{2} \mathrm{~K}$ (e.g., forced water cooling) is preferable for external cooling; a lower HTC may lead to a fast increase in the junction-to-ambient thermal resistance for $\mathrm{Ga}_{2} \mathrm{O}_{3}$ devices.

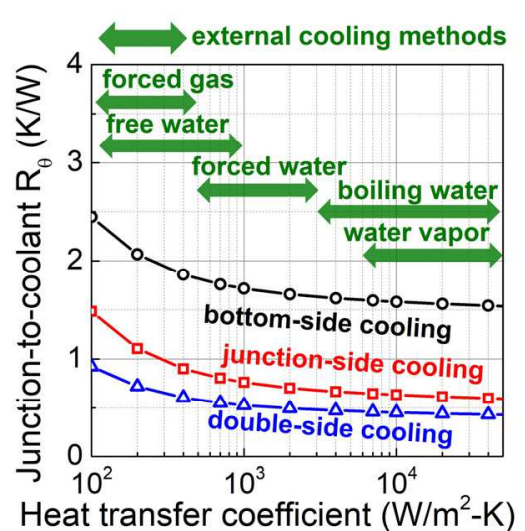

Figure 7. Simulated junction-to-coolant thermal resistance of the $\mathrm{Ga}_{2} \mathrm{O}_{3} \mathrm{SBD}$ as a function of HTC at the case surface, under the bottom-, junction- and double-side cooling. The HTC ranges for different external cooling techniques are marked in green.

For the transient electrothermal ruggedness, the simulation in the previous section has shown that most of the heat does not reach the external surface of the 1-mm Ag plate. Hence, if this Ag plate continues to apply, the external cooling with different HTC is not expected to significantly impact the device's surge current capability. Instead, the device and package structure within the Ag plate are more critical.

To further understand the design space of the surge current capabilities of $\mathrm{Ga}_{2} \mathrm{O}_{3}$ devices, two additional thermal management approaches were considered: thinning of the $\mathrm{Ga}_{2} \mathrm{O}_{3}$ substrate, and bonding $\mathrm{Ga}_{2} \mathrm{O}_{3}$ device layers to a $\mathrm{SiC}$ substrate $(13,14)$. Using the calibrated simulation models, Fig. 8 shows the simulated peak $T_{\mathrm{j}}$ as a function of surge $I_{\text {peak }}$ for the different $\mathrm{Ga}_{2} \mathrm{O}_{3}$ device structures (16). A similarly-rated SiC SBD with identical substrate thickness was also simulated as a reference. In $\mathrm{Ga}_{2} \mathrm{O}_{3}$ devices, the substrate thinning provides little improvement in the surge current capabilities when compared to the use of junction cooling, since most of the heat is directly extracted from the junction. Whereas, if low- $k_{\mathrm{T}} \mathrm{SiC}$ substrate is used in $\mathrm{Ga}_{2} \mathrm{O}_{3}$ devices, the heat extraction through the bulk chip can be improved significantly. Hence, the surge current capabilities can be further improved in the double-side-cooled $\mathrm{Ga}_{2} \mathrm{O}_{3}$-on-SiC device as compared to the bottom-side-cooled one. Finally, the simulation predicts that the $\mathrm{Ga}_{2} \mathrm{O}_{3}$ SBDs on SiC substrate can provide significantly superior surge current capability when 
compared to the similarly-rated $\mathrm{SiC}$ SBDs, as the $\mathrm{Ga}_{2} \mathrm{O}_{3}$-on-SiC SBD combines the inherent thermal stability of $\mathrm{Ga}_{2} \mathrm{O}_{3}$ devices and the high $k_{\mathrm{T}}$ of $\mathrm{SiC}$ substrate.

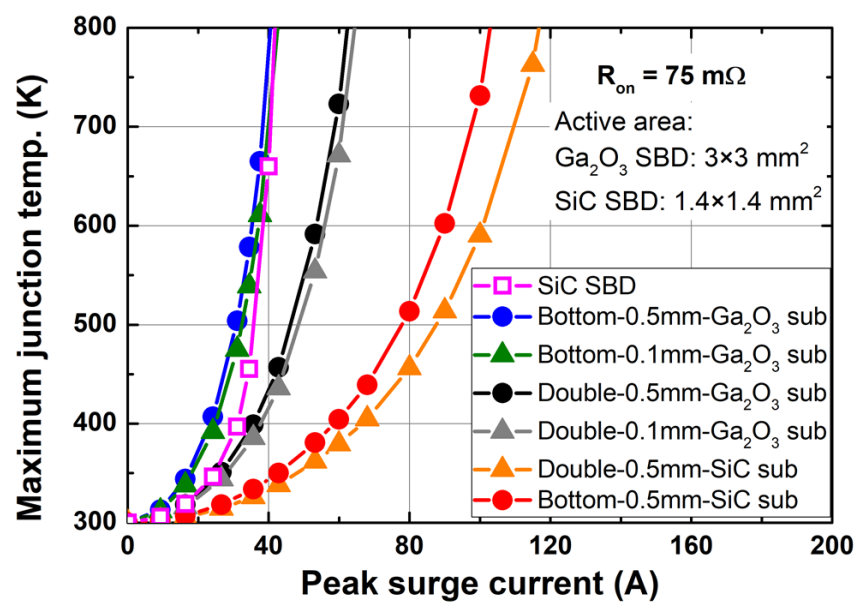

Figure 8. Simulated max peak $T_{\mathrm{j}}$ as a function of peak surge current in 10-ms surge tests for the double-side-cooled and bottom-side-cooled Ga2O3 SBDs on the 0.5-mmthick $\mathrm{Ga}_{2} \mathrm{O}_{3}$ substrate, 0.1 -mm-thick $\mathrm{Ga}_{2} \mathrm{O}_{3}$ substrate, and 0.5 -mm-thick SiC substrate. A thermal boundary resistance of $0.01 \mathrm{~K} /\left(\mathrm{W} \cdot \mathrm{cm}^{2}\right)$ was set at the $\mathrm{Ga}_{2} \mathrm{O}_{3} / \mathrm{SiC}$ bonding interface. Identical electrical conductivity was set for $\mathrm{Ga}_{2} \mathrm{O}_{3}$ and $\mathrm{SiC}$ substrates. The simulated $\mathrm{SiC}$ SBD has a 0.5 -mm-thick substrate and a bottom-side-cooled package.

Caughey-Thomas model was used for the SiC electron mobility.

\section{Summary}

The low $k$ of $\mathrm{Ga}_{2} \mathrm{O}_{3}$ is a key roadblock to remove for the industrial applications of any $\mathrm{Ga}_{2} \mathrm{O}_{3}$ power and RF devices. To ensure the relevance to future applications, we believe that the thermal management of $\mathrm{Ga}_{2} \mathrm{O}_{3}$ devices has to be studied in the context of large-area, packaged device or, in the future, the power modules. This is because many thermal parameters revealed in small-area devices cannot be scaled to predict the performance of large-area devices by simply considering the device area enlargement, not to mention the electro-thermal coupled parameters such as the surge current capability.

To this end, we for the first time demonstrated the large-area $\mathrm{Ga}_{2} \mathrm{O}_{3}$ devices with different packaging configurations and measured the thermal resistance and surge current capabilities of these packaged $\mathrm{Ga}_{2} \mathrm{O}_{3}$ devices. We found that, contrary to some popular belief, $\mathrm{Ga}_{2} \mathrm{O}_{3}$ devices with proper packaging can achieve high thermal performance in both short transients and the steady state. The double-side-packaged $\mathrm{Ga}_{2} \mathrm{O}_{3}$ Schottky rectifiers show a junction-to-case thermal resistance lower than that of the similarly-rated commercial $\mathrm{SiC}$ Schottky rectifiers. In addition, these double-side-packaged $\mathrm{Ga}_{2} \mathrm{O}_{3}$ rectifiers can survive a higher peak surge current as compared to $\mathrm{SiC}$ rectifiers. The critical enabler for these excellent performances is the direct junction cooling with minimal heat going through the $\mathrm{Ga}_{2} \mathrm{O}_{3}$ chip. Strategies for further improving the transient and steady-state thermal performance of $\mathrm{Ga}_{2} \mathrm{O}_{3}$ devices have been identified, with the former being the transfer of $\mathrm{Ga}_{2} \mathrm{O}_{3}$ device layers to low- $k_{\mathrm{T}}$ substrate, and the latter being the addition of external cooling technologies. Our work proves the viability of $\mathrm{Ga}_{2} \mathrm{O}_{3}$ devices for high power applications, manifests the significance of packaging for their die- 
level thermal management, and suggests some new capabilities that $\mathrm{Ga}_{2} \mathrm{O}_{3}$ devices can enable for power electronics.

\section{Acknowledgments}

The Virginia Tech authors acknowledge the partial support by the National Science Foundation under Grant ECCS-2100504 and the High Density Integration Industry Consortium of the Center for Power Electronics Systems, Virginia Tech.

\section{References}

1. S. J. Pearton, J. Yang, P. H. Cary, F. Ren, J. Kim, M. J. Tadjer, and M. A. Mastro, "A review of Ga2O3 materials, processing, and devices," Appl. Phys. Rev., vol. 5, no. 1, p. 011301, Jan. 2018, doi: 10.1063/1.5006941.

2. M. Higashiwaki and G. H. Jessen, "Guest Editorial: The dawn of gallium oxide microelectronics," Appl. Phys. Lett., vol. 112, no. 6, p. 060401, Feb. 2018, doi: $10.1063 / 1.5017845$.

3. N. Allen, M. Xiao, X. Yan, K. Sasaki, M. J. Tadjer, J. Ma, R. Zhang, H. Wang, and Y. Zhang, "Vertical Ga $2 \mathrm{O}_{3}$ Schottky Barrier Diodes With Small-Angle Beveled Field Plates: A Baliga's Figure-of-Merit of $0.6 \mathrm{GW} / \mathrm{cm}^{2}$," IEEE Electron Device Lett., vol. 40, no. 9, pp. 1399-1402, Sep. 2019, doi: 10.1109/LED.2019.2931697.

4. Y. Zhang and T. Palacios, "(Ultra)Wide-Bandgap Vertical Power FinFETs," IEEE Trans. Electron Devices, vol. 67, no. 10, pp. 3960-3971, Oct. 2020, doi: 10.1109/TED.2020.3002880.

5. W. Li, K. Nomoto, Z. Hu, T. Nakamura, D. Jena, and H. G. Xing, "Single and multi-fin normally-off $\mathrm{Ga} 2 \mathrm{O} 3$ vertical transistors with a breakdown voltage over 2.6 kV," in 2019 IEEE International Electron Devices Meeting (IEDM), Dec. 2019, p. 12.4.1-12.4.4, doi: 10.1109/IEDM19573.2019.8993526.

6. P. Paret, G. Moreno, B. Kekelia, R. Kotecha, X. Feng, K. Bennion, B. Mather, A. Zakutayev, S. Narumanchi, S. Graham, and S. Kim, "Thermal and Thermomechanical Modeling to Design a Gallium Oxide Power Electronics Package," in 2018 IEEE 6th Workshop on Wide Bandgap Power Devices and Applications (WiPDA), Oct. 2018, pp. 287-294, doi: 10.1109/WiPDA.2018.8569139.

7. B. K. Mahajan, Y.-P. Chen, J. Noh, P. D. Ye, and M. A. Alam, "Electrothermal performance limit of $\beta-\mathrm{Ga} 2 \mathrm{O} 3$ field-effect transistors," Appl. Phys. Lett., vol. 115, no. 17, p. 173508, Oct. 2019, doi: 10.1063/1.5116828.

8. C. Yuan, Y. Zhang, R. Montgomery, S. Kim, J. Shi, A. Mauze, T. Itoh, J. S. Speck, and S. Graham, "Modeling and analysis for thermal management in gallium oxide field-effect transistors," J. Appl. Phys., vol. 127, no. 15, p. 154502, Apr. 2020, doi: 10.1063/1.5141332.

9. B. Chatterjee, K. Zeng, C. D. Nordquist, U. Singisetti, and S. Choi, "Device-Level Thermal Management of Gallium Oxide Field-Effect Transistors," IEEE Trans. Compon. Packag. Manuf. Technol., vol. 9, no. 12, pp. 2352-2365, Dec. 2019, doi: 10.1109/TCPMT.2019.2923356.

10. N. A. Blumenschein, N. A. Moser, E. R. Heller, N. C. Miller, A. J. Green, A. Popp, A. Crespo, K. Leedy, M. Lindquist, T. Moule, S. Dalcanale, E. Mercado, M. Singh, J. W. Pomeroy, M. Kuball, G. Wagner, T. Paskova, J. F. Muth, K. D. Chabak, and 
G. H. Jessen, "Self-Heating Characterization of $\beta$-Ga2O3 Thin-Channel MOSFETs by Pulsed I - V and Raman Nanothermography," IEEE Trans. Electron Devices, vol. 67, no. 1, pp. 204-211, Jan. 2020, doi: 10.1109/TED.2019.2951502.

11. J. W. Pomeroy, C. Middleton, M. Singh, S. Dalcanale, M. J. Uren, M. H. Wong, K. Sasaki, A. Kuramata, S. Yamakoshi, M. Higashiwaki, and M. Kuball, "Raman Thermography of Peak Channel Temperature in $\beta$-Ga2O3 MOSFETs," IEEE Electron Device Lett., vol. 40, no. 2, pp. 189-192, Feb. 2019, doi: 10.1109/LED.2018.2887278.

12. B. Chatterjee, A. Jayawardena, E. Heller, D. W. Snyder, S. Dhar, and S. Choi, "Thermal characterization of gallium oxide Schottky barrier diodes," Rev. Sci. Instrum., vol. 89, no. 11, p. 114903, Nov. 2018, doi: 10.1063/1.5053621.

13. W. Xu, Y. Wang, T. You, X. Ou, G. Han, H. Hu, S. Zhang, F. Mu, T. Suga, Y. Zhang, Y. Hao, and X. Wang, "First Demonstration of Waferscale Heterogeneous Integration of Ga2O3 MOSFETs on SiC and Si Substrates by Ion-Cutting Process," in 2019 IEEE International Electron Devices Meeting (IEDM), Dec. 2019, p. 12.5.1-12.5.4, doi: 10.1109/IEDM19573.2019.8993501.

14. Y. Zhang and K. J. Chen, "Overcoming the limitations of gallium oxide through heterogeneous integration," Sci. China Phys. Mech. Astron., vol. 64, no. 1, p. 217331, Aug. 2020, doi: 10.1007/s11433-020-1596-5.

15. C. Buttay, H.-Y. Wong, B. Wang, M. Xiao, C. Dimarino, and Y. Zhang, "Surge current capability of ultra-wide-bandgap Ga2O3 Schottky diodes," Microelectron. Reliab., vol. 114, p. 113743, Nov. 2020, doi: 10.1016/j.microrel.2020.113743.

16. M. Xiao, B. Wang, J. Liu, R. Zhang, Z. Zhang, C. Ding, S. Lu, K. Sasaki, G.-Q. Lu, C. Buttay, and Y. Zhang, "Packaged Ga2O3 Schottky Rectifiers With Over 60-A Surge Current Capability," IEEE Trans. Power Electron., vol. 36, no. 8, pp. 85658569, Aug. 2021, doi: 10.1109/TPEL.2021.3049966.

17. B. Wang, M. Xiao, J. Knoll, C. Buttay, K. Sasaki, G.-Q. Lu, C. Di Marino, and Y. Zhang, "Low Thermal Resistance $(0.5 \mathrm{~K} / \mathrm{W})$ Ga2O3 Schottky Rectifiers with Double-Side Packaging," IEEE Electron Device Lett., early access online, 2021, doi: 10.1109/LED.2021.3089035.

18. B. Wang, M. Xiao, X. Yan, H. Y. Wong, J. Ma, K. Sasaki, H. Wang, and Y. Zhang, "High-voltage vertical Ga2O3 power rectifiers operational at high temperatures up to $600 \mathrm{~K}, "$ Appl. Phys. Lett., vol. 115, no. 26, p. 263503, Dec. 2019, doi: $10.1063 / 1.5132818$.

19. "TRANSIENT DUAL INTERFACE TEST METHOD FOR THE MEASUREMENT OF THE THERMAL RESISTANCE JUNCTION-TO-CASE OF SEMICONDUCTOR DEVICES WITH HEAT FLOW THROUGH A SINGLE PATH | JEDEC." https://www.jedec.org/standards-documents/docs/jesd51-14-0 (accessed Apr. 10, 2021).

20. J. Liu, R. Zhang, M. Xiao, S. Pidaparthi, H. Cui, A. Edwards, L. Baubutr, C. Drowley, and Y. Zhang, "Surge Current and Avalanche Ruggedness of 1.2-kV Vertical GaN p-n Diodes," IEEE Trans. Power Electron., vol. 36, no. 10, pp. 10959-10964, Oct. 2021, doi: 10.1109/TPEL.2021.3067019.

21. H. Y. Wong, M. Xiao, B. Wang, Y. K. Chiu, X. Yan, J. Ma, K. Sasaki, H. Wang, and Y. Zhang, "TCAD-Machine Learning Framework for Device Variation and Operating Temperature Analysis With Experimental Demonstration," IEEE J. Electron Devices Soc., vol. 8, pp. 992-1000, 2020, doi: 10.1109/JEDS.2020.3024669. 
22. H. Dhillon, K. Mehta, M. Xiao, B. Wang, Y. Zhang, and H. Y. Wong, "TCADAugmented Machine Learning With and Without Domain Expertise," IEEE Trans. Electron Devices, pp. 1-6, 2021, doi: 10.1109/TED.2021.3073378.

23. Y. Zhang, A. Dadgar, and T. Palacios, "Gallium nitride vertical power devices on foreign substrates: a review and outlook," J. Phys. Appl. Phys., vol. 51, no. 27, p. 273001, 2018, doi: 10.1088/1361-6463/aac8aa.

24. Y. Zhang, A. Zubair, Z. Liu, M. Xiao, J. A. Perozek, Y. Ma, and T. Palacios, "GaN FinFETs and trigate devices for power and RF applications: review and perspective," Semicond. Sci. Technol., vol. 36, no. 5, p. 054001, Mar. 2021, doi: 10.1088/13616641/abde17.

25. M. Xiao, X. Gao, T. Palacios, and Y. Zhang, "Leakage and breakdown mechanisms of GaN vertical power FinFETs," Appl. Phys. Lett., vol. 114, no. 16, p. 163503, Apr. 2019, doi: 10.1063/1.5092433.

26. Y. Zhang, H. Y. Wong, M. Sun, S. Joglekar, L. Yu, N. A. Braga, R. V. Mickevicius, and T. Palacios, "Design space and origin of off-state leakage in GaN vertical power diodes," in 2015 IEEE International Electron Devices Meeting (IEDM), Dec. 2015, p. 35.1.1-35.1.4, doi: 10.1109/IEDM.2015.7409830.

27. J. Liu, M. Xiao, R. Zhang, S. Pidaparthi, C. Drowley, L. Baubutr, A. Edwards, H. Cui, C. Coles, and Y. Zhang, "Trap-Mediated Avalanche in Large-Area $1.2 \mathrm{kV}$ Vertical GaN p-n Diodes," IEEE Electron Device Lett., vol. 41, no. 9, pp. 13281331, Sep. 2020, doi: 10.1109/LED.2020.3010784.

28. J. P. Kozak, R. Zhang, J. Liu, K. D. T. Ngo, and Y. Zhang, "Degradation of SiC MOSFETs under High-Bias Switching Events," IEEE J. Emerg. Sel. Top. Power Electron., early access online, 2021, doi: 10.1109/JESTPE.2021.3064288.

29. J. P. Kozak, R. Zhang, J. Liu, K. D. T. Ngo, and Y. Zhang, "Physics of Degradation in SiC MOSFETs Stressed by Overvoltage and Overcurrent Switching," in 2020 IEEE International Reliability Physics Symposium (IRPS), Apr. 2020, pp. 1-6, doi: 10.1109/IRPS45951.2020.9128330.

30. J. P. Kozak, R. Zhang, H. Yang, K. D. T. Ngo, and Y. Zhang, "Robustness Evaluation and Degradation Mechanisms of SiC MOSFETs Overstressed by Switched Stimuli," in 2020 IEEE Applied Power Electronics Conference and Exposition (APEC), Mar. 2020, pp. 1135-1140, doi: 10.1109/APEC39645.2020.9124313.

31. T. Wang, X. Chen, G.-Q. Lu, and G.-Y. Lei, "Low-Temperature Sintering with Nano-Silver Paste in Die-Attached Interconnection," J. Electron. Mater., vol. 36, no. 10, pp. 1333-1340, Oct. 2007, doi: 10.1007/s11664-007-0230-5.

32. J. N. Calata, T. G. Lei, and G.-Q. Lu, "Sintered nanosilver paste for hightemperature power semiconductor device attachment," Int. J. Mater. Prod. Technol., vol. 34, no. 1-2, pp. 95-110, Jan. 2009, doi: 10.1504/IJMPT.2009.022406.

33. Y. Avenas, L. Dupont, and Z. Khatir, "Temperature Measurement of Power Semiconductor Devices by Thermo-Sensitive Electrical Parameters-A Review," IEEE Trans. POWER Electron., vol. 27, no. 6, p. 12, 2012.

34. H. Wang, M. Xiao, K. Sheng, T. Palacios, and Y. Zhang, "Switching Performance Analysis of Vertical GaN FinFETs: Impact of Interfin Designs," IEEE J. Emerg. Sel. Top. Power Electron., vol. 9, no. 2, pp. 2235-2246, Apr. 2021, doi: 10.1109/JESTPE.2020.2980445.

35. M. Xiao, R. Zhang, D. Dong, H. Wang, and Y. Zhang, "Design and Simulation of GaN Superjunction Transistors With 2-DEG Channels and Fin Channels," IEEE J. 
Emerg. Sel. Top. Power Electron., vol. 7, no. 3, pp. 1475-1484, Sep. 2019, doi: 10.1109/JESTPE.2019.2912978.

36. R. Zhang, J. P. Kozak, M. Xiao, J. Liu, and Y. Zhang, "Surge-Energy and Overvoltage Ruggedness of P-Gate GaN HEMTs," IEEE Trans. Power Electron., vol. 35, no. 12, pp. 13409-13419, Dec. 2020, doi: 10.1109/TPEL.2020.2993982.

37. Y. Zhang, M. Sun, Z. Liu, D. Piedra, H. S. Lee, F. Gao, T. Fujishima, and T. Palacios, "Electrothermal Simulation and Thermal Performance Study of GaN Vertical and Lateral Power Transistors," IEEE Trans. Electron Devices, vol. 60, no. 7, pp. 2224-2230, Jul. 2013, doi: 10.1109/TED.2013.2261072. 